\title{
Ethics and regulation
}

\author{
Bert Gordijn · Wim Dekkers
}

Published online: 3 September 2009

(C) Springer Science+Business Media B.V. 2009

The historical growth of several applied ethics fields - such as animal, environmental, business and research ethics - is to a certain extent scandal driven. Moral concern and public awareness of ethical problems have triggered the development of codes, rules and declarations and other regulatory policies. However, these regulatory instruments do not always effectively address the original concerns. The first paper of this issue is a case in point. David C. Malloy et al. conducted focus groups with physicians from culturally dissimilar countries. They investigated the physicians' level of awareness and the perceived utility of ethical guidelines intended to direct their practice. The overall sense was that they were ineffective, despite the cross-cultural nature of the study. Ethical guidelines were valued only if congruent with existing personal morality. Naturally, this finding questions the relevance of ethical guidelines when it comes to guidance or education. Hence, the authors suggest further analysis of the purpose, content, and delivery of ethical guidelines in order to improve their effectiveness in encouraging ethical behaviour.

Klaus Lindgaard Hoeyer and Niels Lynöe take up the challenge. When ethics is transformed into policy, the link between problems and solutions is far from simple. Specific policies cannot be explained completely by reference to the original moral concerns. Other organizational factors steer the development of concerns into policy. As a result the policies adopted may end up addressing other problems or having other effects than those originally intended. Against this backdrop the authors propose an interesting

B. Gordijn $(\bowtie) \cdot$ W. Dekkers

Faculty of Humanities and Social Sciences, Dublin City

University, Henry Grattan Building, Office No: C163,

Glasnevin, Dublin 9, Ireland

e-mail: bert.gordijn@dcu.ie new approach to the analysis of history and function of ethics policies and their complex practical implications.

In "Refining deliberation in bioethics" Miguel Kottow argues that the rapid growth and the multidisciplinary origin of bioethics have made the discipline vulnerable to criticism. Its discourse has become alarmingly complex and lacks unity. As a result there is a divide between academic bioethics and ordinary citizens and practitioners trying to cope with ethical problems relying on common sense and intuitions. Against this backdrop Kottow proposes new ways of ongoing, participative and structured bioethical deliberation.

Next, Michael Barilan focuses on Nozick's famous "refutation of hedonism" in his thought experiment of the 'Experience Machine', a machine that would give one any experience one desired by directly stimulating one's brain. Nozick examined the question of whether one should "plug into" the experience machine for the rest of one's life (Nozick 1974). Barilan argues that end-of-life-suffering that is resistant to state-of-the-art palliation provides an interesting analogy to Nozick's experiment validating his findings.

In the following paper, Joseph L. Verheijde, Mohamed Y. Rady and Joan L. McGregor advance arguments questioning the validity of the well known and widely accepted Harvard Medical School brain-death criteria to define human death. They argue that there are scientific uncertainties of determining states of impaired consciousness including brain death that necessitate further debate, claiming that organ procurement from patients with impaired consciousness might be seen as a concealed practice of physician-assisted death.

Joris Gielen, Stef Van den Branden and Bert Broeckaert continue the focus on end-of-life issues. They evaluate the operationalisation of religion and world view in published 
quantitative studies surveying nurses' attitudes toward euthanasia and assisted suicide. Their findings demonstrate that in most studies the operationalisation of religion and world view is quite narrow, not reflecting the intricacy of religion and world view in modern societies. Therefore, the authors recommend that future research pay more attention to religion's different dimensions.

Subsequently, Aviad E. Raz and Silke Schicktanz examine the attitudes of lay people, patients and relatives of patients in Germany and Israel towards genetic testing in an exploratory qualitative study. Although the attitudes of respondents affected by genetic diseases were rather similar in both countries, their findings demonstrate remarkable national differences as well.

Interestingly, Gerben Meynen explores the similarities and differences between medical assessments of competence to consent to treatment and criminal responsibility. Thus far, these two medical assessments have been distinct domains. The author argues that, in spite of the differences, both practices could benefit from cooperative research.
The last three papers centre on emerging technologies. Dario Sacchini et al. advance methods for better integrating ethical analysis into Health Technology Assessment. Next, Leen Trommelmans, Joseph Selling and Kris Dierickx tackle the question of whether ex-vivo tissue engineering is a new paradigm in medicine. Finally, Aimee van Wynsberghe and Chris Gastmans take a critical look at the claim that telepsychiatry can improve patient care for populations in general as well as for those in rural and remote locations. In the process they elucidate the significance of in-person contact in the therapeutic relationship.

\section{Reference}

Nozick, R. 1974. Anarchy, state, and Utopia. New York: Basic Books. 